\title{
End-User Flexibility in the Local Electricity Grid - Blurring the Vertical Separation of Market and Monopoly?
}

\author{
Endre Bjørndal \\ NHH Norwegian School of \\ Economics \\ endre.bjorndal@nhh.no \\ Mette Bjørndal \\ NHH Norwegian School of \\ Economics \\ mette.bjorndal@nhh.no
}

\author{
Magnus Buvik \\ NHH Norwegian School of \\ Economics \\ magnus.buvik@gmail.com \\ Christian Nærup Børke \\ NHH Norwegian School of \\ Economics \\ christianboerke@gmail.com
}

\author{
Eivind Gramme \\ Skagerak Nett \\ eivind.gramme@skagerakenergi
}

no

\begin{abstract}
In the Norwegian electricity system, new consumption patterns and changing load profiles increase an already apparent need for reinvestment in the aging network infrastructure. This is very costly, and network operators consider alternative ways of increasing capacity, which are less costly and more flexible. One such option is end-user flexibility. In the paper, we give an overview of the Norwegian electricity market and regulation and the potential of end-user flexibility. We present an investment case provided by a network company, which illustrates that the choice of compensation method to customers have a large impact on the cost and/or revenue cap in the regulatory model. By issuing direct payments for flexibility services, end-user flexibility results in a lower efficiency, although the revenue cap may be higher, while redistribution of network tariffs have a marginal effect on efficiency and the revenue cap. Through redistribution of network tariffs, the network operator can defer investments without a notable change in the revenue cap or change in efficiency. This highlights some of the future challenges that the regulator faces in setting a regulatory framework for end-user flexibility and it challenges the vertical separation that has been a corner stone in the deregulated electricity market.
\end{abstract}

\section{Introduction}

The unique physical properties of electricity define how electricity systems are designed. Since supply and demand must be perfectly balanced at all times, changes in demand must be matched by a similar change in supply. Furthermore, the electricity system is built to be a redundant network. To ensure a reliable electricity supply and a sufficient safeguard against loss of power, network operators determine investments based on the hours of peak load in a year. This often results in significant investments in network capacity to ensure that reliability and safety standards are met. Thus, optimizing investment decisions through smarter electricity system solutions is highly prioritized by Norwegian network operators.

The global trends of electrification, decentralization and digitalization increase the focus on finding innovative ways of planning and upgrading the electricity system infrastructure. The trends introduce a plethora of new solutions to the network operator. To ensure a secure and stable supply of electricity, exploiting flexible resources and capabilities in the electricity system is highlighted as a promising way forward. However, utilizing flexible capacities in the electricity system is not a new concept. With a tight relationship between supply and demand, flexible generation and production has been implemented by large generators and producers at the transmission level of the Norwegian electricity systems for several years. Since technological advances mainly occur at the distribution level of the electricity system, there is a large, untapped potential in utilizing flexibility at the end-user level. This type of end-user flexibility can be used to shift consumption in periods of peak-load, mitigating the need for costly investments in network infrastructure.

With an increasing share of decentralized energy production, Europe's highest EV penetration rate and an aging and mature infrastructure, new and costefficient ways of securing sufficient capacity is a priority. On the other hand, the Norwegian electricity system is well equipped for the challenges of the 
future. With $98 \%$ of all electricity production coming from flexible and renewable hydro power energy, mature and multinational markets with satisfying liquidity in the day-ahead, intra-day and real time market and power tariffs being introduced by 2021, Norway could get a head start in terms of smart electricity infrastructure management compared to the rest of Europe.

In this paper, we discuss the design of the Norwegian electricity market, and how end-user flexibility can be of value in the Norwegian electricity system. We provide an overview over different benefits and applications of end-user flexibility described in the literature. By means of a case study, we discuss how Norwegian network operators can utilize end-user flexibility to defer investments in network infrastructure. It is clear that the way the DSOs can compensate end-users have a large effect on the profitability of using end-user flexibility. This is due to the incentive model in the regulation of the network monopolies, and illustrates that the vertical separation that has been a corner stone of the deregulation of the electricity market so far, may be challenged by the developments of smart grid solutions and more active consumers in the local grids.

\section{Vertical separation in the Norwegian electricity system}

To ensure a reliable, safe and cost-efficient supply of electricity, responsibilities and tasks are assigned to different participants in the electricity system. The responsibility of the Transmission System Operator (TSO) is to ensure operation and development of the transmission network, and to control frequency. In Norway, there is only one TSO, Statnett. The Distribution System Operators (DSOs) own and operate the distribution networks within different regions, and are responsible for supplying end-users with electricity. There are 105 DSOs in Norway. The TSO and DSOs are responsible for transporting electricity and controlling overload and voltage. In Norway, entering a contract with a DSO is mandatory for consumers in order to receive electricity. Consumers are not free to choose the DSO, as operators have monopoly within their respective regions. The monopoly situation for DSOs and the TSO is a result of the deregulation process that occurred in the early 90 s.

However, a competitive market exists for the purchase and sale of electricity. Consumers are free to choose which retailer to buy their electricity from. When providing electricity to end-users, the retailer purchases electricity from generators at the Power
Exchange (PX), or by off-exchange trading through bilateral contracts. The producers and DSOs pay the TSO for being connected to and using the transmission network, whilst consumers pay to the DSOs.

Norwegian power generation is dominated by hydro power $(>95 \%)$, although recently, there has been an increase in renewable generation, especially wind power. Total storage capacity is about $70 \%$ of the Norwegian demand.

\subsection{The wholesale market}

The current market regime consists of several wholesale market places. The trading in the different markets is mostly in a sequential manner, determined by how close to real-time operation one trades. The main part of the wholesale market is the day-ahead market operated by Nord Pool and Euphemia, the latter representing the joint European market place. In this market, buyers and sellers submit their bid curves for every single hour in the following day. The power exchange finds the prices that match demand (purchase) and supply (sales) hour by hour. Because of intermittent production and unplanned outages, participants can also trade in the intraday market to ensure balance. As opposed to the day-ahead market, which is cleared simultaneously for all hours of the day, the intraday market is cleared continuously. The bids and corresponding commitments are aggregated at zonal levels in both markets.

The bids from the day-ahead and intraday markets have an hourly resolution that ensures market balance in the planning phase. However, to ensure real time balance, the TSO organizes reserve markets with different time horizons. The reserves are primarily dispatchable, large generators that increase or decrease generation to stabilize the frequency. The market participants calculate and report deviations between planned and metered sale and purchase, after each single operational hour. The economic consequences of any imbalances are settled by the TSO in accordance to imbalance prices. Both the day-ahead, intraday and reserves market share the common objective of ensuring balance between generation and load in the most efficient way.

\subsection{The end-user market}

Most consumers purchase their electricity from a retailer. The terms are specified through a supply contract between each consumer and a freely chosen retailer. The retailer takes part in the wholesale market and is responsible for assuring balance on behalf of their group of consumers. This part of the market is 
denoted as the end-user side or demand side of the market. Contracts with fixed or variable prices are most common for consumers with periodically metered consumption. Variable price contracts usually have a fixed price for a period, for example based on the area prices (usually monthly prices). Another contract follows the market price from the day-ahead market. Since prices vary hourly, the aggregated consumption for a consumer in a period is distributed, in accordance to a pre-defined profile, to calculate an average price per $\mathrm{kWh}$. Larger consumers with hourly meters can have contracts that settles according to hourly consumption and corresponding hourly market prices. Changes in consumption metering are currently being undertaken by the industry.

Network contracts with the local DSO have a different contract structure. These contracts mainly cover the DSOs expenses related to operation, maintenance and reinforcement of the distribution network. In addition to covering costs, the contracts aim to distribute expenses fairly among the network consumers.

\subsection{Incentive based regulation of distribution grids}

To promote efficient energy markets and costeffective energy systems, a revenue cap regulation was introduced by NVE in 1997 . The revenue cap regulation is part of the regulation on economic and technical reporting, revenue cap for network operators and tariffs (Olje- og Energidepartementet, 2017). The revenue cap should cover the network operator's costs and give a reasonable return on assets under the assumption of efficient operation, reasonable maintenance and network development. When calculating a company's cost-efficiency, the regulator uses Data Envelopment Analysis (DEA) for the benchmarking (NVE, 2017e).

The revenue cap for the forthcoming year is notified by NVE in November the year in advance, and network operators set their tariffs accordingly. All data, results and calculations are published to ensure transparency and understanding of the methodology. The Revenue cap for each company is calculated from the actual total costs two years back, adjusted for inflation and price changes, and a cost norm, using the yardstick formula:

$$
R C_{t}=(1-\rho) C_{t}+\rho C_{t}^{*}
$$

where $R C_{t}$ is the revenue cap for period $t, C_{t}$ is the company's cost, and $C_{t}{ }^{*}$ is the cost norm calculated from the benchmarking. $\rho$ is the weight of the cost norm, and in Norway, $\rho$ is presently equal to 0.6 . The size of $\rho$ reflects the strength of the efficiency incentives in the regulation model (Amundsveen and Kvile, 2015).

The total cost includes operation and maintenance costs (OPEX), capital expenses (CAPEX) consisting of linear depreciations on book values and interest based on the regulated rate of return, that the regulator (NVE) sets every year. Moreover, the cost includes losses in MWh priced at the system price from the electricity market (Nord Pool), and finally a quality element, KILE, which is a calculation of the value of lost load (VOLL). Figure 1 shows the total cost of 119 distribution companies in 2016.

The cost norm, $C_{t}^{*}$, is calculated in three steps: the DEA, a regression analysis to consider geographical differences and a final calibration. The DEA-model used by NVE is an input oriented model with a CRS assumption (Bjørndal et al., 2010). By identifying the most efficient companies, the DEA finds the companies that provide services using the least amount of resources. These companies form the efficiency frontier, and are denoted as reference companies. In the current model for distribution networks, the resources are represented by total costs. The tasks performed by the company are represented by output variables on kilometers of high voltage power lines, number of customers and number of network stations.

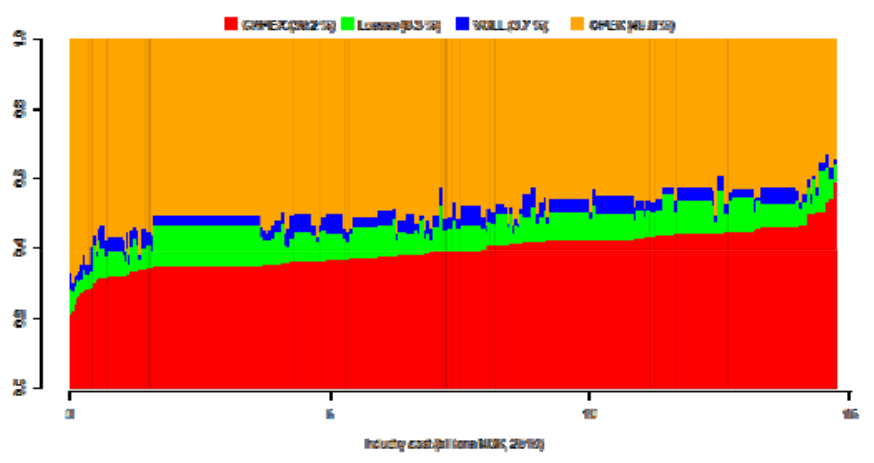

Figure 1. Cost for distribution companies

In the second step, the results of the DEA are adjusted for differences in their operational framework, to provide a more just comparison of the companies. The results are adjusted for differences in topography, climate and network structures using regression analyses.

In the third and final step of the benchmarking exercise, the DEA-results are calibrated such that the average company becomes $100 \%$ efficient. This will give the average network operator a reasonable return on assets, and it ensures that, over time, age differences are taken into consideration. The calibration is 
necessary to give network operators incentives to invest in new assets. Adding up the DEA-norm for the entire industry from step 2 and then subtracting it from the total industry cost, gives the total revenue that is added to companies' revenues. In 2018, this number was approximately 1.5 billion NOK (NVE, $2017 \mathrm{~g}$ ), i.e. a considerable amount. The added revenue is distributed according to the company's regulatory asset base divided by the industry's total regulatory asset base. The larger the added revenue, the greater is the incentive to increase assets through investments.

\subsection{Grid tariffs}

The allowed revenue of a distribution company is collected from the customers, using the principle of two- or multi-part tariffs, i.e. a variable fee to cover marginal cost, and one or more residual parts to make up for the total allowed revenue. The Norwegian system operates with network contracts made up by multiple tariffs, dependent on the consumer's method of metering. Most households currently have periodical meters, and their payments consist of two parts: an energy fee and a fixed fee. The energy fee is usually a semi-fixed price per $\mathrm{kWh}$ multiplied with metered consumption, whilst the fixed fee can be determined based on the size of the main fuse. For some consumers, especially the larger ones, there could be an additional fee based on peak power usage in a period. This fee is known as a power charge, and is usually made up by a fixed price per $\mathrm{kWh} / \mathrm{h}$ per month.

\section{Grid investment needs and alternatives to grid}

In Reiten et al. (2014), four key drivers for estimating future investment needs in the Norwegian electricity system was identified. The first is the technical state of current infrastructure. Substantial network investments occurred in the 1970 and 1980s, and parts of the current infrastructure is approaching the end of its technical lifetime. Ensuring that the overall state of the electricity system is able to handle future electricity demand, load profiles and new appliances is important. Thus, substantial investments are needed at all network levels in the years to come.

The second driver identified was population growth, urbanization and increased electricity demand. A growing population increases electricity demand, thus resulting in a need for new network infrastructure to respond to this increase in demand. Furthermore, population growth rates are higher in urban areas and large cities, meaning that the DSOs in these areas will have higher investment needs than the ones in more remote areas.

A third driver for investments in the electricity system is compliance with national- and international climate goals through increased use of new energy carriers. Although the Norwegian electricity system has benefitted from flexible hydropower, the increased use of renewable power generation challenges the electricity system. Prosumers that sell their energy back to the network will also increase the complexity of the electricity system, highlighting the need for investments.

The fourth and last driver that was highlighted was connected to load increase predictions. The electrification of the transport sector, new power demanding home appliances and the introduction of automatic metering all affect the future load demand, and challenge the network in several ways. The electrification of the transport sector is a critical challenge for the current Norwegian electricity system. Historically, combustion engines and fossil fuels have been used in vehicles, leading to an electricity system that was not dimensioned for a full electrification of this sector. Areas in close proximity to transport centers such as harbors, train- and bus stations will experience increases in power demand with the electrification of the transport sector. This leads to a substantial investment need for capacity increasing investments at the distribution and regional network level.

In addition to these key drivers, the general advances in technology have led to discussions of a "smarter network", where end-user flexibility and flexibility from the demand side is a key component. By involving the end-user through a third-party flexibility aggregator, network operators can access flexibility volumes that are currently hard to obtain for the specific hours when capacity is needed. Since changing consumption patterns challenge the network capacity, flexible end-users can help alleviate peaks and balance demand and supply.

In conclusion, during the period from 2016 to 2025, NVE has estimated investment costs of 33 billion NOK and 15 billion NOK in the high-voltage and lowvoltage parts of the Norwegian distribution network respectively (NVE, 2016). Since investments at the distribution level of the electricity system traditionally has been based on the specific hour in a calendar year where the power output and consumption is estimated to be at its highest, load increase predictions play a vital part in the investment decision network operators undertake. By utilizing end-user flexibility and smarter investment solutions, network operators aim to optimize their network performance while reducing the 
overall investment costs in new infrastructure through better peak load management.

As a consequence, grid companies are looking for alternatives to grid investments in general, including end-user flexibility and new tariffs, but also assessing the effects of a large increase in the number of prosumers, storage capacity and microgrids. THEMA Consulting (2015) made a scenario analysis highlighting the potential uncertainty in Norwegian investment needs, depending on the proliferation of the aforementioned developments. The future use of local grids may imply increased (more rush-hour customers due to electric vehicles and other household appliances) or reduced (end-user flexibility and prosumers) maximum load, more variation in capacity utilization (the grid as a back-up solution) and shorter periods of use.

\section{End-user flexibility - an overview of mechanisms, benefits and applications}

End-user flexibility can be defined as the enduser's ability and capacity to shift, curtail or limit consumption for short or long periods of time. This may be the result of market prices, price incentives in networks tariffs or other mechanisms, potentially not involving economic incentives. Thus, end-user flexibility is a concept that includes a diverse set of dimensions (see also Oren (2013) and Ottesen (2017).

\subsection{Implicit and explicit end-user flexibility}

A common distinction used in the literature is between implicit and explicit end-user flexibility. While implicit end-user flexibility implies that the endusers adjust their consumption patterns according to price signals, explicit end-user flexibility is characterized by incentivizing end-users to trade their flexibility in an organized market place (Ramos et al., 2013).

Implicit end-user flexibility is often referred to as price-based flexibility, and implies that end-users adjust their consumption to price signals or track variations in price through apps or appliances. Common price signals are time based power tariffs such as Time-of-Use (ToU) and Real Time Pricing (RTP), or demand based power tariffs such as Critical Peak Pricing (CPP), which raises the price of electricity when the peak demand is high (EG3, 2015). An example of an appliance that helps end-users adjust their consumption is the application SmartLiv by the Norwegian DSO Ringeriks-Kraft Nett. The application enables end-users to observe their consumption through hourly metering, track shifts in consumption patterns over time and compare their consumption with neighbors and other end-users (Ringeriks-Kraft Nett AS, 2017). Another vital aspect of implicit end-user flexibility deployment is a high time granularity of metering.

Explicit end-user flexibility embodies flexibility that can be traded in a market place. With explicit enduser flexibility, the end-user can be compensated through a contract that enables manual or automatic shifts in their electricity consumption. One of the key drivers for the deployment of explicit end-user flexibility is well-defined and liquid flexibility markets. Since participation in such markets include substantial transaction costs, and since volumes produced from a change in consumption from a single end-user typically does not satisfy the required bid size, a key driver in explicit end-user flexibility deployment is the establishment of aggregators who aggregate flexibility and offer specific flexibility services to the market on behalf of the customer.

The main goal of flexibility services is to enable the end-user to take part in the market place and reduce their electricity costs by offering flexibility to the system through their consumption patterns. In this respect, flexibility services play a vital role in balancing supply and demand in the electricity system. Ultimately, increased end-user flexibility can result in lower electricity prices, which even benefits nonflexible end-users (U.S. Department of Energy, 2017).

Both technology and end-user preferences influence end-user flexibility deployment. Specific flexibility services can only be provided by explicit end-user flexibility, while other services are only possible with implicit end-user flexibility. Explicit enduser flexibility is a measurable resource. Hence, it can be incorporated in system adequacy assessments in a similar way to generation (SEDC, 2016). Implicit enduser flexibility shifts the commitment to the end user's behavioral patterns. With the roll out of automatic meters and increasing customer participation implicit end-user flexibility may have a large untapped potential.

Flexibility from large industrial players is actively used by the TSO to balance the electrical networks. For imbalances in the distribution network, there is a lack of measures to adjust production or consumption. However, intelligent equipment in the networks may make it possible to utilize end-user flexibility from smaller electricity consumers, such as households and offices. The DSOs may acquire flexibility services both implicitly, from designing appropriate tariffs, and explicitly, by buying flexibility services. 


\subsection{Handling Peak Demand with End-User Flexibility.}

In recent years, end-user flexibility is promoted as a promising way to deal with new load profiles, an increasing share of renewable energy sources and a changing energy demand landscape (Papaefthymiou, Grave, \& Dragoon, 2014). When assessing how to handle peak demand through end-user flexibility deployment in the distribution network, large volumes of end-user flexibility have been hard to obtain for research and modelling purposes. Researchers at ETH Zürich (Geidl, et al., 2007) solved this by studying the interrelation between electrical and thermal energy systems in buildings called Energy Hubs. These Energy Hubs relied on various energy input variables such as electricity, natural gas and heating. Furthermore, the Energy Hubs included storage and conversion properties, and produced output services that complied with certain loads such as electricity, heating and cooling.

Bozchalui et al., (2012) propose a Mixed Integer Linear Programming (MILP) optimization problem to the Energy Hub concept. The problem minimizes energy consumption, cost of energy, emissions and peak load. Specific end-user preferences and comfort levels are also taken into account. The application of the model on a household in Ontario, Canada resulted in up to $20 \%$ savings on energy costs and a $50 \%$ reduction in peak demand, all while satisfying the designated preferences and comfort levels of the enduser.

Strbac et al., (2008) discuss the major benefits and challenges of end-user flexibility in the UK power system. Key benefits include improved management of the demand-supply balance in electricity systems with an increasing share of renewable energy, deferring new infrastructure investments, simplifying outage management and relieving congestion in distribution substations. The use of demand response to better utilize infrastructure capacity is proposed as a large benefit. Strbac highlights the lack of ICT systems to support demand response and end-user flexibility deployment, immature and insufficient market design as well as lacking provision of incentives from OFGEM, the UK regulator.

\subsection{End-User Flexibility in Investment Decisions.}

The traditional approach to expanding capacity in the network is investing directly in physical infrastructure. Hoff, Wenger and Farmer (1996) highlights that demand-driven investments in increased capacity often results in a period of excess capacity. Furthermore, the cost benefit of deferring investments results from the specific investment costs and time they are deferred (Wang, et al., 2008). In an early study, Román, Gómez, Muñoz, \& Peco (1999) proposes the use of geographic information systems (GIS) to model and plan network investments alongside roads and transport infrastructure. They conclude that this approach reduced barriers and infeasibilities in network planning.

El Khattam, Hegazy \& Salama (2005) proposes a new model for network investments where the positioning and sizing of distributed generation (DG) sources are optimized. Several investment alternatives are tested, including expanding an existing substation and adding new feeders to purchasing power from an existing intertie to meet load demand growth. They conclude that optimizing this positioning and sizing can result in a $20 \%$ reduction in investment costs.

Méndez et al., (2006) also studies the impact of DG on deferring distribution network investments. A main result from their research is that with $0 \%$ penetration of DG, load increases in the distribution network can grow by $171.4 \%$ until reaching an overload probability of $0.5 \%$, while a $30 \%$ penetration of DG allows a load increase of $196.4 \%$ until reaching an overload probability of $0.5 \%$. They also highlight that DG plants with solar PV generation allow higher load growths before making network reinvestments than DG plants with wind power generation. This is due to a higher randomness in wind energy production.

Piccolo \& Siano (2009) discusses how DG can serve as an alternative distribution planning option by providing opportunities to capture the deferment benefit. They highlight the regulatory side of the issue and conclude that European legislations must be revised to make DG a feasible option to investments in infrastructure. By obliging network operators to require for local power generation as a direct alternative to network infrastructure reinvestments, the deferral benefits of DG can be reaped.

Pudjianto et al., (2013) introduces smart control to minimize distribution network reinforcements. They simulate how network infrastructure investments differs in a business-as-usual scenario and a Smart Grid scenario. Without smart infrastructure management, they estimate that between 2010 and 2050 , the total distribution network reinforcements in the UK will amount to $£ 36$ billion. By applying smart charging of vehicles, smart heat pumps and optimized control of network voltage regulators, they conclude that there is a substantial savings potential in infrastructure investment costs. The report does not explicitly estimate any savings. 
Spiliotis, Ramos and Belmans (2016) analyze how end-user flexibility can be used to solve capacity problems and defer physical network expansions in the distribution network. They develop and define the FlexMart model, which enables the DSO to purchase end-user flexibility offered by residential end-users. The model works as a long-term planning tool and provide an optimal combination of physical expansions, flexibility deployment and dispatch to reassure capacity needs in network operations are met.

\subsection{Quantifying the Technical Potential of End-User Flexibility.}

The technical potential can be described as the amount of flexibility end-users can offer to the electricity system. Several research projects have studied and quantified the flexibility potential in Norway and the Nordic region.

An early study conducted by Meland et al., in 2006, estimated the technical potential of end-user flexibility by considering electricity volumes that could be replaced by other energy carriers. This study focused on office buildings, residential homes and industrial complexes. The flexible load is estimated partly by assuming plausible changes in energy carriers and by assuming an average time of 2000 hours each year. The study concluded that by switching energy carriers, 2700 to $4000 \mathrm{MW}$ of flexibility were made available.

In a SINTEF-study from 2010, Sæle \& Grande estimates the technical potential in Norwegian households by analyzing results from a pilot by the DSO Malvik Everk. The results from the pilot was an estimated reduction in power output of 1 to $2,5 \mathrm{kWh} / \mathrm{h}$ per end-user, depending on whether they were equipped with hot water boilers or water based residential heating systems respectively. By scaling these results based on a $50 \%$ acceptance rate of automated control of warm water tanks nationally, the study concluded that the technical potential in these Norwegian households amounted to $1000 \mathrm{MW}$.

Xrgia \& EC Group (2012) estimated the technical potential of end-user flexibility in the Norwegian counties of Oslo and Akershus. Based on electricity consumption statistics, estimates of future power outtakes and qualitative assessments of end-user flexibility deployment, an estimated technical potential of $550 \mathrm{MW}$ in Oslo and Akershus was found.

The technical potential of end-user flexibility will also be influenced by a growing fleet of EV's. In the report "Does the electrical network have enough capacity to include electrical buses, ferries and cars?" from 2017, NVE estimates that each additional EV represent an increase of $0.7 \mathrm{~kW}$ in peak demand. The current fleet of roughly $125000 \mathrm{EVs}$ accounts for 100
MW in potential flexibility. This does not account for the technical potential in charging appliances in the Norwegian distribution network (Statistisk Sentralbyrå, 2017).

Even though the electricity systems in Norway and Sweden are slightly different, both countries possess long-term storage and flexibility solutions in hydropower generation, and have integrated electricity markets through Nord Pool. Comparing technical potential between the two countries is thus a feasible approach. In 2016, The Swedish Energy Market Inspectorate (EI) conducted an extensive study of the technical potential of end-user flexibility in Sweden. The technical potential in Sweden was estimated to almost $8000 \mathrm{MW}$ in the winter months with $5500 \mathrm{MW}$ of this potential being supplied by residential endusers. In the summer months, the estimated flexibility was $3700 \mathrm{MW}$, with $1700 \mathrm{MW}$ being supplied by residential end-users.

An earlier Swedish project, Elforsk, studied the possibility of curtailing electric heating and water heater loads. An average controllable load of 4-5 kW per house at 10-15 degrees below zero implied a technical potential of approximately $1500 \mathrm{MW}$ in Sweden (Elforsk, 2006).

Gaia Consulting (2011) estimated the practical potential for end-user flexibility in the Nordic region. The research highlighted that most of the flexibility potential is in Swedish and Norwegian households, with some flexibility available in Finnish households and a very limited flexibility potential in Danish households. The results relied heavily on economical, technical and practical assumptions, but estimated the end-user flexibility potential in the Nordic region to between 4000 MW and 7000 MW, excluding flexibility from the industry. From this potential flexibility, between $1000 \mathrm{MW}$ and $3500 \mathrm{MW}$ originated from Norwegian end-users.

In summary, several attempts of quantifying the technical potential of end-user flexibility has been conducted, both in Norway and abroad. However, it is not clear from these research projects if this potential stems from explicit- or implicit end-user flexibility. In a report from 2016, COWI Belgium highlighted that roughly $92 \%$ of potential peak reductions induced by end-user flexibility deployment would come from explicit end-user flexibility. The remaining $8 \%$ would come from price based programs and implicit end-user flexibility.

\subsection{Dynamic Pricing, Tariffs and End-User Flexibility.}

Faruqui \& Sergici (2010) review 15 different Demand Response pilots in the U.S, Canada, Australia 
and France. All pilots target peak demand reductions through dynamic electricity pricing. The review conclude that ToU-rates induce a peak demand reduction of 3 to $6 \%$, while CPP-tariffing induce a peak demand reduction of 13 to $20 \%$. Faruqui and Sergici highlight that by accounting for enabling technologies, the CPP-tariffing leads to a peak demand reduction of 27 to $44 \%$ due to different compensation mechanisms.

Bartusch et al. (2011) analyze how end-users respond to a demand based ToU-tariff. By utilizing this indirect control contract, a Swedish DSO wanted to investigate how they could reduce peak load in their distribution network. The study concludes that endusers respond positively to being charged according to this type of tariff. Furthermore, the introduction of the tariff decreased the peak demand substantially.

In a later study, Bartusch et al. (2014) study the effect of a power tariff on electricity consumption in a residential area of Stockholm. The attitude to shift consumption were measured over a long period, where the researchers tested the attitude over six years. The research concluded that although the attitude to shift consumption from times of high demand of electricity to times of low demand of electricity were significant, it was not reflected through an actual shift in consumption over time.

Haring \& Andersson (2014) highlight the need for incentive based rewarding contracts when pursuing direct control flexibility mechanisms. Efficient contracts between the prosumer and central agent must be individually rational and incentive compatible. To make contracts individually rational, the end-user must be rewarded and not make a loss from entering the flexibility contract. Incentive compatibility occurs when the end-user receives incentives to display and share their actual flexibility costs. By introducing a non-linear framework of pricing, capacity reservation and deployment of reserve energy are being rewarded separately.

Another viable business model is proposed by Campaigne and Oren (2016). By utilizing a fuse control paradigm, flexibility aggregators impose capacity constraints on prosumers or penalize them for breaching a capacity threshold. Subsequently, the prosumers allocate the available electricity to separate devices. The contract between the flexibility aggregator and the prosumer is seasonal, and typically allow the aggregator to curtail consumption over time given a certain probability of curtailment.

\subsection{Trading End-User Flexibility in Flexibility Markets.}

Eid et al. (2016) discuss a flexibility market design inspired by the French trading system and markets for flexibility in both the short-, medium- and long-term trading periods. In the French trading system, minimum bid capacities for balancing services have been reduced from $50 \mathrm{MW}$ to $10 \mathrm{MW}$ to motivate smaller parties like independent aggregators to participate in the balancing markets. The research is based on five markets; ancillary services, system balancing and network congestion management, spot markets and generation capacity markets.

Zhang et al. (2014) introduces a clearinghouse concept for flexibility called FLECH at the distribution level. The FLECH market utilizes aggregator-based offers to promote small scale DERs with up to 5MW for their active market participation. In this market design, the compensation is stipulated by the capacity needs of the DSO. The aggregator then responds to this capacity need by bidding prices and quantities of flexibility, and the FLECH market runs single-side auctions or super market trading where the aggregator designs specific flexibility products that are presented to the end-users.

A third, bid-less flexibility market design is presented by Gantenbein et al. (2012). By updating and publishing prices in five-minute intervals, customers can respond to this price continuously by shifting their load (Larsen, et al., 2015).

ENFO (2016) discuss a "traffic light regulation" of monopoly and market functions in the electricity system, which was first proposed by Eurelectric (2014) in their report "Active Distribution System Management". This system is based on the need for specific option schemes for Norwegian DSO's. Separating monopoly- and market activities makes it possible to introduce new products that enables the end-user to participate in the market.

\section{Case study}

The case study is provided by Skagerak Nett, a DSO in southern Norway, and it illustrates how enduser flexibility can be used to defer investments, in this particular case, in upgrading the capacity of two transformers in a substation. The increased capacity is necessary both to handle peak load and to provide reserve in case of component malfunction.

The DSO considers two different Scenarios concerning the use of flexibility. In scenario 1, enduser flexibility is used only in case of malfunction in the transformers. In the second scenario, end-user 
flexibility is used in case of malfunctions as well as to handle peak loads in normal operations. The scenarios represent two possible applications that the industry considers valuable and feasible, and both may help to defer capacity-increasing investments.

Another dimension studied by the DSO is the sources of flexibility, i.e. who will provide the flexibility services to the DSO. In the following, F1 includes industrial consumers that are already flexible to the TSO, while F2 also includes a tentative flexibility from households, assuming that $1 / 3$ of the households in the area will provide 1 and $1.5 \mathrm{~kW}$ in off-peak and peak hours respectively.

Three different load increase predictions are considered: a $34 \%$ increase in load until 2040, as well as a $16 \%$ increase and $0 \%$ increase.

Load increases and component malfunctions have traditionally been resolved by direct investments in capacity increasing assets and reserves, and end-user flexibility is presented as an alternative technology. We discuss four alternatives or cases, one traditional investment case, which serves as the base case, and three cases with different compensation schemes for end-user flexibility:

1. Investing in capacity increase without any use of end-user flexibility.

2. Compensating flexible end-users through discounted network tariffs.

3. Compensating flexible end-users through an availability payment of 20,000 NOK per MWh and an activation payment of 20,000 NOK per MWh.

4. Compensating flexible end-users through an activation payment of 30,000 NOK per MWh.

In order to evaluate the effect on cost, the DSO has used historical data on load, probability of failures, and different cost elements. The compensation levels in the flexibility mechanisms are high, but lower than the value of lost load. If too high, the cost of the flexibility mechanisms will be overestimated.

The alternatives given by the four cases above, have different effects on different cost groups (ref. section 2.3). In the first case, the investment expense will increase CAPEX immediately, while this increase is delayed for the other cases. The DSO invests in the capacity upgrade in all four cases, however at different points in time, given by when the $\mathrm{N}-1$ criterion is no longer met. The OPEX will be higher in cases 2-4, due to switching and repair cost, but also due to the flexibility payment. These costs are however lower in case 2 , since the tariff discounts to flexible consumers will be compensated by higher tariffs to non-flexible consumers (the incentive regulation fixes the total revenue for each company, and the company collects the revenue by two-part tariffs). VOLL and network losses are similar, but these costs, especially losses, are particularly high if the load increase is high. Table 1 summarizes the present value of cost changes over the investment cycle (i.e. until 2040) in different situations.

Table 1. PV of cost.

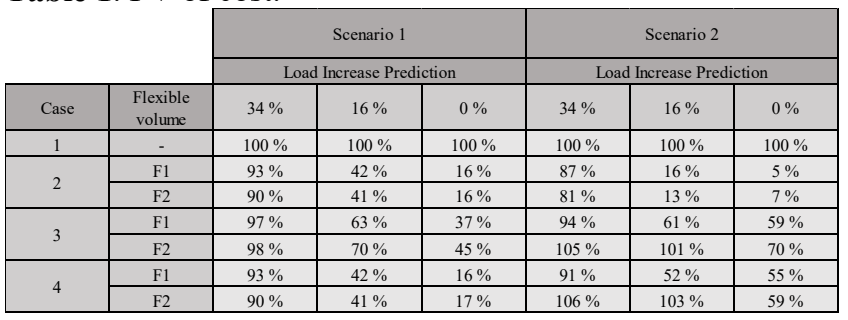

Table 1 shows normalized cost figures (the lower number, the better), with the investment case as the base case $(100 \%)$. In the flexible load cases, investments are deferred by 3-4 years with the high load increase, and by 22 years otherwise. We also note that flexibility is better with lower load increases and if more suppliers can provide flexibility. Moreover, the costs are lower if flexibility is provided by tariff reductions, particularly in the situations where flexibility is much used, i.e. with $16 \%$ or $0 \%$ load increase. This is due to the incentive regulation model, where it is advantageous for the company to avoid cost, since increasing the cost may reduce efficiency scores and costs are not fully compensated in the yardstick model (ref. section 2.3). This illustrates that the vertical separation, that was the starting point of the Norwegian deregulation, is not so straightforward, and that local flexibility markets can influence and interact with the regulation model in unexpected ways. In this case, the compensation mechanism is not neutral under the regulation model, and this may favor some ways of solving a problem at the expense of others.

To understand the full effect on the companies' incomes, we should also calculate the revenue caps. However, these are even more difficult to forecast, since in order to do so, we need to estimate the effects not only on cost, but also on the benchmarking results. This involves estimating the outputs too, and in general what happens to other companies in the industry over several decades. An example for the high load increase is given in table 2, where changes in revenue are normalized relative to case 1 .

From Table 2 we notice that cases 2 and 4 are similar in Scenario 1. This is because flexibility is little used when the load increase is high. Then the flexibility mechanism with high activation payment is better than the one with both activation and availability payment (case 3 ). The choice of compensation method may affect revenues positively or negatively, since the 
larger cost of direct payments for flexibility services on the one hand increases cost and on the other hand decreases efficiency, and thus possibly the cost norm.

Table 2. PV of revenue caps.

\begin{tabular}{c|c|r|r|}
\hline NPV of Change in Revenue Caps (High Load Increase) \\
\hline \multirow{2}{*}{ Case } & $\begin{array}{c}\text { Flexibility } \\
\text { Volume }\end{array}$ & Scenario 1 & Scenario 2 \\
\hline 1 & - & $100 \%$ & $100 \%$ \\
\hline 2 & F1 & $92 \%$ & $91 \%$ \\
& F2 & $89 \%$ & $88 \%$ \\
\hline 3 & F1 & $94 \%$ & $95 \%$ \\
& F2 & $94 \%$ & $101 \%$ \\
\hline \multirow{2}{*}{4} & F1 & $92 \%$ & $94 \%$ \\
& F2 & $89 \%$ & $102 \%$ \\
\hline
\end{tabular}

The most profitable situation occurs when end-user flexibility allows investments to be deferred, and this flexibility can be invoked by tariff redistributions.

\section{Conclusions}

End-user flexibility, together with distributed generation and storage, may provide alternatives to investing and reinvesting in grid capacity in the local networks. From the presented case study, we notice that the choice of compensation method to customers have a large impact on the profitability of the network companies. By issuing direct payments for flexibility services, end-user flexibility may result in a higher revenue cap although efficiency is lower, while redistribution of network tariffs have only a marginal effect on changes in efficiency and revenue cap. Thus, using end-user flexibility to defer network investments is likely to come with a redistribution of regulated network tariffs rather than development of local flexibility markets. This highlights some of the future challenges that the regulator faces in setting a regulatory framework for end-user flexibility, and it challenges the vertical separation that has been a corner stone in the deregulated electricity market.

\section{References}

[1] Amundsveen, R., and H. Kvile, "The Development and Application of an Incentive Regulation Model - A Balancing Act”, Oslo, NVE, 2015.

[2] Bartusch, C., P. Juslin, U. Persson-Fischer, and J. Stenberg, Elkonsumenters drivkrafter för en ökad förbrukningsflexibilitet: Hushålls attityder och anpassningar till en tidsdifferentierad och effektbaserad elnätstariff, Stockholm, Elforsk, 2014.
[3] Bartusch, C., F. Wallin, M. Odlare, I. Vassileva, and L. Wester, "Introducing a demand-based electricity distribution tariff in the residential sector: Demand response and customer perception”, Energy Policy, 2011.

[4] Bjørndal, E., M. Bjørndal, P. Pardalos, and M. Rönnqvist, Energy, Natural Resources and Environmental Economics. New York, Springer, 2010.

[5] Bogetoft, P., and L. Otto, Benchmarking with DEA, SFA and R, New York, Springer, 2011.

[6] Bozchalui, M., S. Hashmi, H. Hassen, and C. Canizares, Optimal Operation of Residential Energy Hubs, IEEE, 2012.

[7] Campaigne, C., and S. Oren, "Firming renewable power with demand response: an end-to-end aggregator business model", Journal of Regulatory Economics, 2016.

[8] COWI Belgium, Impact Assessment Study on Downstream Flexibility, Price Flexibility, Demand Response \& Smart Metering, COWI Belgium, 2016.

[9] EG3, Regulatory Recommendations for the Deployment of Flexibility, Expert Group 3, 2015.

[10] EI, Åtgärder för ökad efterfrågeflexibilitet i det svenska elsystemet, Stockholm, Elmarknadsinspektionen, 2016.

[11] El-Khattam, W., Y. Hegazy, and M. Salama, "An integrated distributed generation optimization model for distribution system planning”, IEEE, 2005.

[12] ENFO, Fleksibilitet - fremtidig organisering av monopol og marked, Energi Norge, 2016.

[13] Eurelectric, Flexibility and Aggregation: Requirements for their interaction in the market, Eurelectric, 2014.

[14] Funk, S., and J. Wood, Can demand response help reduce future distribution grid investments: An economic study of peak shaving in the Norwegian distribution grid, NHH, 2017.

[15] Gaia Consulting, Examining and proposing measures to activate demand flexibility on the Nordic wholesale electricity market, Gaia Consulting, 2011.

[16] Geidl, M., K. Gaudenz, P. Favre-Perrod, K. Bernd, G. Andersson, and K. Frohlich, Energy Hubs for the Future, IEEE, 2007.

[17] Haring, T., and G. Andersson, Contract design for demand response, IEEE, 2014.

[18] Hoff, T.E., H.J. Wenger, and B.K. Farmer, "Distributed generation: An alternative to electric utility investments in system capacity”, Energy Policy, 1996, pp. 137-147. 
[19] Larsen, E., P. Pinson, G. Le Ray, and G. Giannopoulos, Demonstration of market-based real-time electricity pricing on a congested feeder, 12th International Conference on the European Energy Market (EEM). Lisbon, Portugal, IEEE, 2015.

[20] Meland, P., A. Tjeldflåt, and T. Wahl, Forbrukerfleksibilitet i det nordiske kraftmarkedet, Oslo, NVE, 2006.

[21] V. H. Mendez, J. Rivier, J. I. de la Fuente, T. Gomez, J. Arceluz, J. Marin, A. Madurga, "Impact of distributed generation on distribution investment deferral", Int. J. Elect. Power Energy Syst., 2006, pp. 244-252.

[22] NVE, Status og Prognoser for Kraftsystemet, NVE, Oslo, 2016.

[23] NVE, Kostnadsnormen, 2017a.

[24] NVE, Inntektsrammer, $2017 \mathrm{~b}$.

[25] Olje- og Energidepartementet, Forskrift om økonomisk og teknisk rapportering, inntektsramme for nettvirksomheten og tariffer, Oslo, The Norwegian Government, 2017.

[26] Oren, S.S., "A historical perspective and business model for load response aggregation based on priority service", Proceedings of the 46th HICSS Conference, Hawaii, 2013, pp. 2206-2214.

[27] Ottesen, S., Techno-economic models in Smart Grids: Demand side flexibility optimization for bidding and scheduling problems, Department of Industrial Economics and Technology Management, NTNU, 2017.

[28] Papaefthymiou, G., K. Grave, and K. Dragoon, Flexibility options in electricity systems, Ecofys, 2014.

[29] Piccolo, A. and P. Siano, "Evaluating the impact of network investment deferral on distributed generation expansion", IEEE Transactions on Power Systems, 2009, pp. 1559-1567.

[30] Pudjianto, D., P. Djapic, M. Aunedi, C. Gan, G. Strbac, S. Huang, and D. Infield, "Smart control for minimizing distribution network reinforcement cost due to electrification", Energy Policy, 2013.

[31] Ramos, A., C. De Jonghe, D. Six, and R. Belmans, "Asymmetry of information and demand response incentives in energy markets", Stockholm: IEEE, 2013.

[32] Ringeriks-Kraft Nett AS, Ringeriks-Kraft Nett Smart:Liv, $\quad$ https://www.ringerikskraft.no/privat/strom/smartliv/, November 28, 2017.

[33] Reiten, E., L. Sørgård, and K. Bjella, Et bedre organisert strømnett, Oslo, 2014.
[34] Sæle, H. and O. Grande, Demand Response From Household Customers, IEEE, 2010.

[35] SEDC, Explicit and Implicit Demand-Side Flexibility: Complementary Approaches for an Efficient Energy System, Brussels, Smart Energy Demand Coalition, 2016.

[36] Sergici, S., and A. Faruqui, "Household response to dynamic pricing of electricity: a survey of 15 experiments", Journal of Regulatory Economics, 2010.

[37] Spiliotis, K., A. Ramos, and R. Belmans, "Demand flexibility versus physical network expansions in distribution grids", Applied Energy, 2016.

[38] Statistisk Sentralbyrå, Registrerte Kjøretøy, 2017.

[39] Strbac, G., "Demand side management: Benefits and challenges", Energy Policy, 2008.

[40] THEMA Consulting, Framtidens Nett: Utfordringer og muligheter for nettselskapene, Oslo, 2015.

[41] U.S. Department of Energy, https://energy.gov/oe/activities/technologydevelopment/grid-modernization-and-smart-grid/demandresponse, October 20, 2017.

[42] Wang, C. and H. Z. Cheng, "Optimization of network configuration in large distribution systems using plant growth simulation algorithm", IEEE Transactions on Power Systems, 2008, pp. 119-126.

[43] Xrgia \& EC Group, Nettplan Stor-Oslo: Alternativer til nettinvesteringer, Oslo, Statnett SF, 2012.

[44] Zhang, C., Y. Ding, N. Nordentoft, P. Pinson, and J. Østergaard, "FLECH: A Danish market solution for DSO congestion management through DER flexibility services", Journal of Modern Power Systems and Clean Energy, 2014. 